\title{
Clinical role of brexpiprazole in depression and schizophrenia
}

\author{
This article was published in the following Dove Press journal: \\ Therapeutics and Clinical Risk Management \\ 10 March 2017 \\ Number of times this article has been viewed
}

\section{Nishant B Parikh \\ Diana M Robinson \\ Anita H Clayton}

Psychiatry and Neurobehavioral Sciences, University of Virginia School of Medicine, Charlottesville, VA, USA

Correspondence: Anita H Clayton Psychiatry and Neurobehavioral Sciences, University of Virginia School of Medicine, PO Box 800623, Charlottesville, VA 22908 USA

Email ahc8v@virginia.edu
Abstract: Brexpiprazole, a serotonin-dopamine activity modulator, is the second $\mathrm{D}_{2}$ partial agonist to come to market and has been approved for the treatment of schizophrenia and as an adjunctive treatment in major depressive disorder. With less intrinsic activity than aripiprazole at the $\mathrm{D}_{2}$ receptor and higher potency at $5-\mathrm{HT}_{2 \mathrm{~A}}, 5-\mathrm{HT}_{1 \mathrm{~A}}$, and $\alpha 1_{\mathrm{B}}$ receptors, the pharmacological properties of brexpiprazole suggest a more tolerable side effect profile with regard to akathisia, extrapyramidal dysfunction, and sedation. While no head-to-head data are currently available, double-blind placebo-controlled studies show favorable results, with the number needed to treat (NNT) vs placebo of 6-15 for response in acute schizophrenia treatment and 4 for maintenance. NNT is 12 for response and 17-31 for remission vs placebo in major depression. In schizophrenia trials, treatment-emergent adverse effects (TEAEs) and discontinuation rates due to TEAEs were lower in treatment groups vs placebo $(7.1 \%-9.2 \%$ vs $14.7 \%$, respectively). Meanwhile, discontinuation rates due to TEAEs in depression studies were higher in treatment groups vs placebo $(1.3 \%-3.5 \%$ vs $0-1.4 \%$, respectively) and appeared dose dependent. Rates of akathisia are lower compared to those with aripiprazole and cariprazine, weight gain is more prominent than with aripiprazole, cariprazine, or ziprasidone, and sedation is less than with aripiprazole but more than with cariprazine. Brexpiprazole target dosing is $2-4 \mathrm{mg}$ in schizophrenia and $2 \mathrm{mg}$ in depression augmentation. Dose adjustments should be considered in hepatic or renal dysfunction and/or in poor cytochrome P450 2D6 metabolizers. While brexpiprazole represents an exciting second entry for $\mathrm{D}_{2}$ partial agonists with positive studies thus far, direct head-to-head comparisons will shed more light on the efficacy and side effect profile of brexpiprazole.

Keywords: serotonin-dopamine activity modulator, antipsychotic, partial agonist, psychopharmacology

\section{Introduction}

Schizophrenia and depressive disorders account for a significant portion of the world's disease burden. According to the Global Burden of Disease Study, schizophrenia causes a high degree of disability, accounting for $1.1 \%$ of the total disability-adjusted life years (DALYs) and $2.8 \%$ of years lived with disability (YLDs). ${ }^{1}$ It is approximated that schizophrenia affects 21 million people worldwide and carries the highest disability weight of the 220 diseases examined in the Global Burden of Disease Study. ${ }^{2}$ Major depression affects 121 million people ${ }^{3}$ and accounted for $8.2 \%$ of global YLDs and dysthymia accounted for another $1.4 \% .{ }^{4}$ Major depression explains 16 million suicide DALYs and nearly 4 million ischemic heart disease DALYs. ${ }^{5}$ By 2020, it is expected to become the second leading contributor of DALYs in all ages behind heart disease. ${ }^{3}$

Both schizophrenia and major depression are disorders that are a challenge to treat due to their remitting-relapsing nature, associated suicide risks, and impact on neurocognitive function that impair global functioning including help-seeking behavior. Current 
psychopharmacologic options carry the challenges of limited efficacy and issues with tolerability with common adverse effects including, but not limited to weight gain, sedation, and akathisia. Brexpiprazole (branded as Rexulti) is a serotonindopamine activity modulator ${ }^{6}$ approved in July 2015 for treatment of schizophrenia and as an adjunctive treatment in major depressive disorder (MDD). ${ }^{7}$ Brexpiprazole may offer another option in the range of options for treatment.

\section{Pharmacology}

The primary strategy for schizophrenia treatment has been to inhibit dopamine neurotransmission via dopamine receptor antagonism. First-generation antipsychotics, while effective in treating positive symptoms, often result in numerous treatment-emergent adverse effects (TEAEs), not limited to metabolic side effects of glucose metabolism issues and weight gain, endocrine effects such as hyperprolactinemia, and central nervous effects such as sedation, cognitive slowing, and extrapyramidal symptoms. Second-generation agents include other receptor activities such as antagonism of 5- $\mathrm{HT}_{2 \mathrm{~A}}$ receptors and $\alpha_{1}$-adrenoreceptors as an effort to mitigate these adverse effects. ${ }^{6} \mathrm{D}_{2}$ partial agonism became another approach, stabilizing dopamine function while mitigating side effects. Aripiprazole was the first $\mathrm{D}_{2}$ partial agonist to be approved for the treatment of schizophrenia, bipolar mania, and bipolar mania and as an augmenting agent in major depression. The activation, agitation, and akathisia associated with aripiprazole have been ascribed to its high level of intrinsic activity at the $\mathrm{D}_{2}$ receptor. ${ }^{8}$

Brexpiprazole, also a dopamine partial agonist, has less intrinsic activity than aripiprazole - a step closer to $\mathrm{D}_{2}$ antagonism on the agonist-antagonist spectrum. Along with less intrinsic ability, brexpiprazole has greater potency than aripiprazole with regard to $5-\mathrm{HT}_{2 \mathrm{~A}}$ antagonism, $5-\mathrm{HT}_{1 \mathrm{~A}}$ agonism, and $\alpha 1_{B}$ antagonism, actions that have been shown to reduce akathisia and extrapyramidal symptoms. Brexpiprazole has also been shown to induce neurite outgrowth mediated through $5-\mathrm{HT}_{1 \mathrm{~A}}$ and $5-\mathrm{HT}_{2 \mathrm{~A}}$ receptors and subsequent $\mathrm{Ca}^{2+}$ signaling via $\mathrm{IP}_{3}$ receptors. ${ }^{9}$ Additionally, brexpiprazole binds less strongly than aripiprazole to $\mathrm{H} 1$ receptors, suggesting less antihistaminic activity resulting in less sedation, somnolence, and weight gain. With the glutamate theory of schizophrenia in mind, brexpiprazole was also shown to improve $N$-methyl-D-aspartate (NMDA) receptor antagonist phencyclidine-induced cognitive deficits in novel object recognition test and dizocilpine-induced social recognition deficits in rodents. ${ }^{10,11}$ As a $\mathrm{D}_{2}$ partial agonist with less intrinsic activity and with the secondary receptor characteristics abovementioned, the hope is for an antipsychotic that remains effective at $\mathrm{D}_{2}$ modulation while simultaneously having an improved side effect profile.

\section{Pharmacokinetics}

Brexpiprazole is metabolized by liver cytochrome P450 (CYP P450) 3A4 and 2D6 enzymes. It is possible that drugs that inhibit and induce 3A4 (common psychotropic inducers: carbamazepine; common inhibitors: fluvoxamine, fluoxetine) or 2D6 (common psychotropic inhibitors: paroxetine, fluoxetine, duloxetine, bupropion, asenapine) may have an interaction. Brexpiprazole itself does not influence the activity of CYP P450 metabolic enzymes. ${ }^{12}$ It has a half-life of 91 hours and thus has a lower risk of withdrawal symptoms with missed doses but takes longer to reach steady state and for elimination from the body. As a result, steady-state concentrations occur within 10-12 days of initial dosing or changes. Oral bioavailability is $95 \%$ and peak plasma concentrations are reached within 4 hours of dosing. Most drug and inactive metabolites are excreted through renal and gastrointestinal systems at a proportion of $25 \%$ and $46 \%$, respectively, shown via radiolabeled brexpiprazole. ${ }^{7}$

\section{Evidence review in schizophrenia}

The objective of the evidence review is not to provide an exhaustive review of all studies conducted but to provide an overview on the available higher powered Phase III studies with a look into relevant secondary outcome measures. Values presented are statistically significant unless otherwise specified. The first 2 studies below serve as the basis of brexpiprazole's approval for schizophrenia by the United States Food and Drug Administration (FDA).

The first Phase III, multicenter, randomized, doubleblind, placebo-controlled trial in 636 patients with schizophrenia compared placebo with $0.25 \mathrm{mg}, 2 \mathrm{mg}$, and $4 \mathrm{mg}$ of brexpiprazole for 6 weeks. The $0.25 \mathrm{mg}$ group did not generate statistically significant improvement, as hypothesized. Response rates, as defined by $\geq 30 \%$ reduction in Positive and Negative Syndrome Scale (PANSS) or Clinical Global Impression Improvement (CGI-I) score of 1 or 2, were $47.8 \%$ with $2 \mathrm{mg}$ and $46.1 \%$ in the $4 \mathrm{mg}$ group compared to $31.7 \%$ in placebo. Both $2 \mathrm{mg}$ and $4 \mathrm{mg}$ groups showed statistically significant improvement over placebo in PANSS total score and CGI Severity (CGI-S) total score. The $2 \mathrm{mg}$ but not the $4 \mathrm{mg}$ group showed significant improvement in the personal and social performance (PSP) scale over placebo (score of 13.15 in $2 \mathrm{mg}$ group vs 10.46 in placebo). PSP in $4 \mathrm{mg}$ group was 12.72 with a $P$-value of 0.06 . In other secondary 
end point measures, including Marder positive and negative symptoms and uncontrolled hostility and excitement, both treatment groups showed significant improvement over placebo. The only subscore showing nonsignificant improvement over placebo was for Marder anxiety/depression. Discontinuation rates due to lack of efficacy were lower in the treatment groups than placebo, with the lowest in the $4 \mathrm{mg}$ group, which was associated with significantly less likelihood of discontinuation of $3.9 \%$ vs placebo at $10.1 \%$. Given the earlier definition of response, the number needed to treat (NNT) would be 6 for $2 \mathrm{mg}$ and 7 for $4 \mathrm{mg} .{ }^{13}$

The second Phase III, multicenter, randomized, doubleblind, placebo-controlled trial in 674 patients with schizophrenia compared placebo with $1 \mathrm{mg}, 2 \mathrm{mg}$, and $4 \mathrm{mg}$ of brexpiprazole. At 6 weeks, the study end point, only the $4 \mathrm{mg}$ treatment group showed statistically significant reduction in PANSS total score compared with placebo (mean difference of -6.47). Other treatment groups showed nonsignificant improvement. Only the $4 \mathrm{mg}$ treatment group showed statistically significant improvement in numerous secondary end points including CGI-S, PSP (along with the $1 \mathrm{mg}$ group), PANSS positive subscale, PANSS negative subscale, PANSS excited subcomponent, and PANSS Marder negative score, Marder disorganized thought score, as well as Marder uncontrolled hostility/excitement scores. Both the $2 \mathrm{mg}$ and $4 \mathrm{mg}$ groups showed significant improvement in CGI-I score and PANSS Marder anxiety/depression score. Discontinuation due to psychiatric TEAEs was higher in the placebo group $(9.2 \%)$ than in the treatment groups $(5.4 \%$ in the $2 \mathrm{mg}$ and $4 \mathrm{mg}$ groups). Discontinuation rates due to lack of efficacy were not significantly different from placebo. Using the earlier definition of response, the NNT was 15 in the $2 \mathrm{mg}$ group and 6 in the $4 \mathrm{mg}$ group. ${ }^{14}$ A pooled analysis of the abovementioned 2 studies showed superiority to placebo in both the $4 \mathrm{mg}(\mathrm{n}=359)$ and $2 \mathrm{mg}(\mathrm{n}=359)$ groups via change from baseline in PANSS total score after 6 weeks of treatment: -6.69 in the $4 \mathrm{mg}$ group and -5.46 in the $2 \mathrm{mg}$ group..$^{15,16}$

A third Phase III multicenter, randomized, double-blind, placebo-controlled, active-reference trial in 468 patients with schizophrenia compared placebo, extended-release quetiapine 400-800 mg, and brexpiprazole 2-4 mg for 6 weeks. In a preliminary analysis, the mean change in the PANSS total score was -20.0 and -15.9 in the brexpiprazole vs placebo groups $(P=0.056)$ with assay sensitivity demonstrated by a change of -24.0 with quetiapine XR $(P<0.001)$. However, on the CGI-S, both brexpiprazole and quetiapine XR showed a statistically significant decrease compared to placebo, but quetiapine resulted in a larger numerical decrease than brexpiprazole ( -1.2 vs -1.4 , respectively). ${ }^{17,18}$

In a multicenter, exploratory, open-label, Phase III positive control trial comparing brexpiprazole and aripiprazole in 97 patients with acute schizophrenia for a 6-week duration, both brexpiprazole (1-4 mg) and aripiprazole (10-20 mg) groups showed decrease from baseline in mean PANSS scores:-22.9 points and -19.4 points, respectively. Other significant differences include a $3.84 \%$ reduction from baseline in impulsivity assessed via the Barratt Impulsiveness Scale version 11, while the aripiprazole group had a $0.14 \%$ increase in score. Response rates were $60.9 \%$ in the brexpiprazole group vs $48.5 \%$ in the aripiprazole group, ${ }^{19}$ with the NNT of 9 with brexpiprazole after aripiprazole failure. However, neither of the last 2 studies discussed were powered for direct comparison.

In a year-long, Phase III, randomized, double-blind, placebo-controlled study in patients with a 3-year history of schizophrenia, maintenance treatment with brexpiprazole was compared to placebo after initial stabilization of an acute episode with brexpiprazole. Of the 464 patients who entered the initial treatment phase, 202 achieved stabilization and were randomized to treatment. Significant differences between brexpiprazole and control groups include lower PANSS by 4.42 points across all time points, higher PSP by 4.8 points, and higher global assessment of functioning (GAF) by 6.6 points at the study end point of 52 weeks. ${ }^{20}$ By the study end, $13.5 \%$ of brexpiprazole patients met criteria for relapse vs $38.5 \%$ of placebo patients. Relapse was defined as, 1) CGI-I score $\geq 5$ and increase on any PANSS items P02, P03, P06, and G09 to score $>4$, with score $\geq 2$ on that specific item and absolute increase of $\geq 4$ on combined 4 PANSS items, 2) hospitalization due to worsening of psychosis, 3) suicidal behavior, or 4) violent/aggressive behavior. ${ }^{21}$ Overall, NNT over placebo was $4 .{ }^{22}$

On the whole, the majority of the data available are positive for brexpiprazole use when compared to placebo with relatively low NNT for acute and maintenance treatment. While 2 studies included other antipsychotics, direct comparison at this point is difficult. Most ideally, a head-tohead comparison trial against other atypical antipsychotics, especially aripiprazole, is warranted to have a more clear understanding the role of brexpiprazole in schizophrenia treatment.

\section{Evidence review in depression}

As aforementioned, the review of the evidence presented here is focused on higher powered Phase III studies. FDA approval of brexpiprazole was based on 2 Phase III 
multicenter, randomized, double-blind, placebo-controlled trials. The study populations were 18 - to 65 -year-old patients with MDD without psychosis with current episode lasting for $\geq 8$ weeks and inadequate response to previous antidepressants, as defined by $<50 \%$ reduction in the Antidepressant Treatment Response Questionnaire following a trial of 1-3 antidepressants. Patients had to have a score of $>18$ on the Hamilton Depression Rating Scale (HAMD-17) to be eligible for the study. ${ }^{23}$

The first of these trials evaluated double-blind treatment using adjunctive brexpiprazole $1 \mathrm{mg}$ and $3 \mathrm{mg}$ daily dosing vs adjunctive placebo in a total of 677 patients who had an inadequate response to an 8-week single-blind placebo adjunct to a physician-determined antidepressant, which included escitalopram, fluoxetine, controlled-release paroxetine, sertraline, duloxetine, and extended-release venlafaxine. Notably, 600 of the original 1,539 patients did respond to the singleblinded placebo adjunct and continued for another 6 weeks on placebo plus antidepressant therapy instead of being randomized to treatment groups. Least squares mean improvement in the Montgomery-Asberg Depression Rating Scale (MADRS) in the $3 \mathrm{mg}$ group was 8.29 points over baseline and better by 1.95 points vs the placebo group $(P=0.0079)$. While placebo group and $1 \mathrm{mg}$ group did show improvement, the difference did not reach statistical significance $(P=0.0737)$. Additionally, responder rate was $23 \%$ in the $3 \mathrm{mg}$ group with response defined as $\geq 50 \%$ reduction in MADRS score from baseline. ${ }^{23}$ NNT for response was 12 in the $3 \mathrm{mg}$ group vs placebo adjunct and 31 for remission. ${ }^{22}$

The second, very similarly designed study randomized 379 patients to adjunctive brexpiprazole $2 \mathrm{mg}$ daily vs adjunctive placebo after a single-blind placebo adjunct phase. Again, it is important to note that 331 of the original 826 patients did well with the single-blind placebo adjunct. After 6 weeks of double-blind treatment, the $2 \mathrm{mg}$ group showed least squares mean improvement in MADRS of 8.36 points over baseline, which bettered placebo by 3.21 points. MADRS responder rate in the $2 \mathrm{mg}$ group was $23.4 \%$. The placebo group showed insignificant improvement. ${ }^{24} \mathrm{NNT}$ for response was 12 in the $2 \mathrm{mg}$ group vs placebo adjunct and 17 for remission. ${ }^{22}$ Notably, all brexpiprazole groups, $1 \mathrm{mg}, 2 \mathrm{mg}$, and $3 \mathrm{mg}$, across both studies showed significant reduction in Sheehan Disability Scale from baseline; 1.27, 1.35 , and 1.26 , respectively. ${ }^{23,24}$ A pooled analysis showed an overall $23.2 \%$ rate of treatment response in all adjunctive brexpiprazole groups vs $14.5 \%$ in placebo, giving an overall NNT of $12 .{ }^{22}$ A post hoc analysis of these 2 Phase III studies conducted by McIntyre et al found that brexpiprazole was well tolerated in patients with MDD with anxious distress and was not associated with an increased incidence of akathisia. ${ }^{25}$

Several smaller Phase III studies looked at other symptoms associated with depression and how they responded to an antidepressant plus brexpiprazole $1-3 \mathrm{mg}$ augmentation. One 6-week, open-label, exploratory study in 37 patients with major depression and anxiety symptoms saw improvements in mean scores in MADRS, Hamilton Anxiety Rating Scale, and Kellner's Symptom Questionnaire. ${ }^{26}$ Another open-label exploratory study in 55 patients with major depression and irritability showed improvement in irritability at end point of 6 weeks, but worsening 4 weeks after treatment discontinuation. ${ }^{28} \mathrm{~A}$ third open-label exploratory study in 44 patients with major depression and sleep disturbances showed improvements via polysomnography and sleep diary in sleep efficiency, total sleep time, sleep onset latency, and wake time after sleep onset. Score improvements were seen in Insomnia Severity Index, Epworth Sleepiness Scale, and Cognitive and Physical Functioning Questionnaire. ${ }^{29}$

Overall, the data examined appear to be in support of brexpiprazole as an effective agent over placebo with NNTs of 12 for response and 17-31 for remission. No studies comparing brexpiprazole with aripiprazole or other antipsychotic augmenting agents in major depression exist although 1 trial comparing brexpiprazole with extended-release quetiapine in MDD is currently in the process of recruiting participants. $^{30}$

\section{Safety and tolerability}

Overall, completion rates in the Phase III studies examined were between $91.3 \%$ and $95.6 \%$ in depression augmentation groups vs $93.2 \%-94.1 \%$ in placebo. ${ }^{23,24}$ In schizophrenia studies, completion rate in treatment groups (excluding $0.25 \mathrm{mg}$ group) ranged from $67.2 \%$ to $70.7 \% \mathrm{vs}$ $59.2 \%-64.1 \%$ with placebo. ${ }^{13,14}$

In schizophrenia studies, discontinuation events were overall higher with placebo than for treatment groups. ${ }^{13}$ Brexpiprazole TEAEs were $7.1 \%-9.2 \%$ in the $1-4 \mathrm{mg}$ groups vs $14.7 \%$ in the placebo treatment group, with the most common TEAE being worsening of schizophrenia. ${ }^{22}$ Withdrawal rates due to adverse events during a year-long maintenance phase treatment were $6.2 \%$ for brexpiprazole vs $11.5 \%$ in placebo. ${ }^{21}$ In depression studies, discontinuation rates due to TEAEs were higher in treatment groups $(1.3 \%-3.5 \%)$ and appeared dose dependent vs placebo $(0-1.4 \%) .{ }^{22}$ Withdrawal rate due to adverse events in pooled data from 2-year-long studies in depression was $13.8 \% .^{31}$ 
Table I Rates of akathisia in schizophrenia and MDD

\begin{tabular}{|c|c|c|c|c|c|}
\hline Study & Diagnosis & Dose & Brexpiprazole (\%) & Placebo (\%) & Comments \\
\hline \multirow[t]{3}{*}{ Correll et al ${ }^{13}$} & $\mathrm{SCH}$ & $0.25 \mathrm{mg}$ & 0 & 2.2 & Significant tardive dyskinesia and severe \\
\hline & & $2 \mathrm{mg}$ & 4.4 & & akathisia excluded prior to study inclusion \\
\hline & & $4 \mathrm{mg}$ & 7.2 & & \\
\hline \multirow[t]{3}{*}{ Kane et al ${ }^{14}$} & $\mathrm{SCH}$ & $\mathrm{I} \mathrm{mg}$ & 4.2 & 7.1 & \\
\hline & & $2 \mathrm{mg}$ & 4.8 & & \\
\hline & & $4 \mathrm{mg}$ & 6.5 & & \\
\hline \multirow[t]{4}{*}{ Correll et al ${ }^{15, *}$} & $\mathrm{SCH}$ & $0.25 \mathrm{mg}$ & 0 & 4.6 & \\
\hline & & $\mathrm{l} \mathrm{mg}$ & 4.2 & & \\
\hline & & $2 \mathrm{mg}$ & 4.6 & & \\
\hline & & $4 \mathrm{mg}$ & 6.9 & & \\
\hline \multirow[t]{3}{*}{ Thase et $\mathrm{a}^{23,24}$} & MDD & $\mathrm{Img}$ & 4.4 & $1.0-2.3$ & \\
\hline & & $2 \mathrm{mg}$ & 7.4 & & \\
\hline & & $3 \mathrm{mg}$ & 13.5 & & \\
\hline
\end{tabular}

Note: *Pooled Correll et al ${ }^{13}$ and Kane et al. ${ }^{14}$

Abbreviations: MDD, major depressive disorder; $\mathrm{SCH}$, schizophrenia.

Akathisia in schizophrenia trials occurred in the first 3 weeks of treatment, but no one discontinued due to this side effect. ${ }^{13,14}$ Table 1 shows the rates of akathisia in treatment groups compared to placebo for patients with schizophrenia and MDD. In an open-label trial comparing brexpiprazole with aripiprazole, the overall rate of EPS-related adverse effects with brexpiprazole was $14.1 \%$ vs $30.3 \%$ in the aripiprazole group. ${ }^{19}$ Adequately powered studies comparing brexpiprazole with other antipsychotic medications are not available. The amount of weight gain in $\mathrm{kg}$ for short- and long-term trials of brexpiprazole for schizophrenia and MDD is shown in Table 2. Table 3 compares and contrasts the first-line oral second-generation antipsychotic medication calculations of number needed to harm $(\mathrm{NNH})$ for weight gain, somnolence, and akathisia.

Weight gain in schizophrenia trials of brexpiprazole ranged from $1.23 \mathrm{~kg}$ to $1.89 \mathrm{~kg}$ above baseline vs $0.35-0.42 \mathrm{~kg}$ with placebo. ${ }^{13,14}$ Among these patients, $8.8 \%-12.2 \%$ had $\geq 7 \%$ increase in body weight over the 6-week study periods. ${ }^{19}$ In long-term studies in depression, mean weight gain was $3.1 \mathrm{~kg}$ over baseline at week 52 and weight gain was the most frequent adverse effect leading to treatment withdrawal. ${ }^{31}$
A total of $29.5 \%$ of the patients in the long-term study had a $\geq 7 \%$ increase in body weight. ${ }^{31}$ In depression studies, weight gain was $1.4-1.64 \mathrm{~kg}$ vs $0.37 \mathrm{~kg}$ in placebo at the end of 6 weeks. ${ }^{20,21} \mathrm{~A}$ total of $2.2 \%-4.9 \%$ had $\geq 7 \%$ increase in body weight. ${ }^{22}$

Triglyceride (TG) values increased in all treatment groups, as well, with ranges of $5 \%-15 \%$ of patients across short-term schizophrenia and depression studies moving from normal/borderline TG to $\geq 200 \mathrm{mg} / \mathrm{dL}$. A total of $13 \%-17 \%$ of patients experienced TG increase in long-term open-label studies. Only 2 patients across all pooled data experienced TG increase from normal/borderline to $\geq 500 \mathrm{mg} / \mathrm{dL} .{ }^{22}$

Pooled data in schizophrenia show rates of sedation of $2.7 \%$ and $1.6 \%$ in the $4 \mathrm{mg}$ and $2 \mathrm{mg}$ groups, respectively, yielding an overall rate of $2.1 \% .{ }^{22}$ Placebo rates by comparison were $0.8 \% .{ }^{15}$ In depression studies, rates of sedation were $4 \%$ for $1 \mathrm{mg}, 4.3 \%$ for $2 \mathrm{mg}, 5.7 \%$ for $3 \mathrm{mg}$ vs $0.5 \%$ in placebo.

In schizophrenia studies, mean prolactin (PRL) level increased from baseline in the $4 \mathrm{mg}$ group but changes were minimal, $<2 \mathrm{ng} / \mathrm{mL} .{ }^{13}$ A second study showed that PRL increases occurred in $19.1 \%$ of the $4 \mathrm{mg}$ group, $16.4 \%$ of

Table 2 Weight gain in short- and long-term studies of patients with schizophrenia and depression

\begin{tabular}{|c|c|c|c|c|c|c|}
\hline Study & Diagnosis & $\begin{array}{l}\text { Study length } \\
\text { (weeks) }\end{array}$ & $\begin{array}{l}\text { Brexpiprazole } \\
\text { weight gain (kg) }\end{array}$ & $\begin{array}{l}\text { Placebo weight } \\
\text { gain (kg) }\end{array}$ & $\begin{array}{l}\geq 7 \% \text { increase in body } \\
\text { weight (\% of patients) }\end{array}$ & Comments \\
\hline Correll et al ${ }^{13}$ & $\mathrm{SCH}$ & 6 & $1.23-1.89$ & $0.35-0.42$ & $8.8-12.2$ & \\
\hline \multicolumn{7}{|l|}{ Kane et $\mathrm{al}^{14}$} \\
\hline Thase et $\mathrm{al}^{23,24}$ & MDD & 6 & $1.4-1.64$ & 0.37 & $2.2-4.9$ & $\begin{array}{l}\text { Weight gain was the most } \\
\text { frequent adverse event leading } \\
\text { to treatment withdrawal }\end{array}$ \\
\hline Nelson et $\mathrm{al}^{31}$ & MDD & 52 & 3.1 & & 29.5 & \\
\hline
\end{tabular}

Abbreviations: $\mathrm{SCH}$, schizophrenia; MDD, major depressive disorder. 
Table $3 \mathrm{NNH}$ vs placebo for oral second-generation antipsychotics in adults

\begin{tabular}{|c|c|c|c|c|c|c|}
\hline \multirow[t]{2}{*}{ Antipsychotics } & \multicolumn{2}{|c|}{ NNH for weight gain $\geq \mathbf{7} \%$} & \multicolumn{2}{|c|}{$\begin{array}{l}\text { NNH for somnolence adverse } \\
\text { events }\end{array}$} & \multicolumn{2}{|c|}{$\begin{array}{l}\text { NNH for akathisia adverse } \\
\text { events }\end{array}$} \\
\hline & Schizophrenia & $\begin{array}{l}\text { Adjunctive } \\
\text { for MDD }\end{array}$ & Schizophrenia & $\begin{array}{l}\text { Adjunctive } \\
\text { for MDD }\end{array}$ & Schizophrenia & $\begin{array}{l}\text { Adjunctive } \\
\text { for MDD }\end{array}$ \\
\hline Brexpiprazole & 17 & 52 & 50 & 34 & 112 & 15 \\
\hline Aripiprazole & 21 & 22 & $20^{*}$ & 50 & 25 & 5 \\
\hline Cariprazine (to 6 mg/day) & 34 & & 100 & & 15 & \\
\hline Risperidone & $18^{*}$ & & 13 & & 15 & \\
\hline Olanzapine & $6^{*}$ & 3 & $7^{*}$ & II & 25 & 167 \\
\hline Quetiapine IR & 6 & & $10^{*}$ & & ND & \\
\hline Quetiapine XR & 22 & 29 & 7 & 4 & 188 & 91 \\
\hline Ziprasidone & 16 & & 15 & & 100 & \\
\hline Paliperidone & 35 & & 42 & & 38 & \\
\hline Iloperidone & 10 & & 16 & & ND & \\
\hline Asenapine & 35 & & 17 & & 34 & \\
\hline Lurasidone & 67 & & II & & 10 & \\
\hline
\end{tabular}

Notes: Adapted from Citrome L. The ABCs of dopamine receptor partial agonists-aripiprazole, brexpiprazole, and cariprazine: the I5-min challenge to sort these agents out. Int J Clin Pract. 2015;69(II): I2I I-1220, with permission from John Wiley and Sons, copyright 2015. ${ }^{27}$ ND, no difference or rate with medication is lower than rate with placebo. *Pooled schizophrenia and bipolar mania.

Abbreviations: $\mathrm{NNH}$, number needed to harm; MDD, major depressive disorder; XR, extended release; IR, immediate release.

the $2 \mathrm{mg}$ group, $10.5 \%$ of the $1 \mathrm{mg}$ group, and $13.9 \%$ of the placebo groups; however, subjects did not show increases beyond $2 \times$ the upper limit of normal. ${ }^{14}$ One of 181 patients taking $4 \mathrm{mg}$ was discontinued from the trial due to increased blood CPK. ${ }^{14}$ Insomnia and agitation in the treatment groups in a pooled analysis were similar or lower than placebo. ${ }^{15} \mathrm{QT}$ prolongation was minimal. . $^{13,14,22}$

With regard to pregnancy, little data exist as no wellcontrolled studies have been done in humans to examine risk to the fetus. Pregnant rats and rabbits that have received brexpiprazole at doses up to 73 and 146 times the maximum recommended human dose (MRHD) showed no teratogenicity. However, pregnant rats given brexpiprazole at 73 times the MRHD from organogenesis through lactation did have perinatal pup death. The package insert does mention a risk for extrapyramidal symptoms and/or withdrawal in the neonate from mothers who are exposed. ${ }^{7}$ No studies in lactation have been done though brexpiprazole is present in rat milk. ${ }^{7}$

Black box drug class warnings exist for increased mortality risk in elderly patients with dementia-related psychosis and increased suicidal thoughts/behaviors in patients 24 years and younger. Safety has not been established in pediatric patients. $^{7}$

\section{Applications to clinical practice and dosing}

In schizophrenia, brexpiprazole may be considered in those patients who may be especially sensitive to EPS-related side effects or have had issues with somnolence or prolactinemia with other antipsychotic agents. The target dose in schizophrenia is $2-4 \mathrm{mg}$ daily. Recommended titration protocol is to start at $1 \mathrm{mg}$ for 4 days, then to increase to $2 \mathrm{mg}$ for days $5-7$, increasing to the maximum recommended dose of $4 \mathrm{mg}$ on day 8 based on clinical response and tolerability. ${ }^{7}$

In major depression, augmentation with brexpiprazole should be considered after failed trials of antidepressant agents across at least 2 classes of antidepressants for example, selective serotonin reuptake inhibitors and serotonin-norepinephrine reuptake inhibitors. Brexpiprazole should be used in addition to an antidepressant, preferably the one with best effect - even if only a partial effect. In depression the target dose is $2 \mathrm{mg}$ daily with a maximum dose of $3 \mathrm{mg} /$ day. The recommended starting dose is $0.5-1 \mathrm{mg}$ with suggested dose increases at weekly intervals based on efficacy and tolerability.

In both treatment populations, it is recommended that those patients with moderate to severe hepatic or endstage renal impairment should be prescribed no more than $3 \mathrm{mg}$ daily. Doses should be halved in poor CYP P450 2D6 metabolizers or normal metabolizers receiving CYP 2D6 or 3A4 inhibitors. Careful considerations must be taken with regard to cost given the current availability of brexpiprazole as a branded drug only. Weight and lipids should be monitored at a regular interval. For patients $\leq 24$ years old, it is especially important to monitor for new or worsening suicidal thoughts/behaviors.

\section{Conclusion}

The approval of brexpiprazole in 2015 marks the arrival of the second $\mathrm{D}_{2}$ partial agonist to market for the primary treatment 
of schizophrenia and adjunctive therapy for MDD. Though limited, the available data support use of brexpiprazole for both conditions, with NNTs that are encouraging with a favorable side effect profile. Overall, $\mathrm{D}_{2}$ partial agonism is an exciting approach in modulating dopamine transmission, and the success of aripiprazole is inviting for the development and refining of newer agents. In the context of schizophrenia and major depression, both of which demonstrate an accelerating degree of contribution to worldwide disability and disease burden, brexpiprazole exists as another option in a range of treatments for schizophrenia and as an adjunct to MDD therapy. With time, and with adequately powered comparison studies, the efficacy and safety profile of brexpiprazole will be effectively defined.

\section{Disclosure}

Dr Clayton has the following conflicts of interest to declare: Grants: Auspex Pharmaceuticals, Axsome, Forest Research Institute, Inc., Genomind, Inc., Janssen; Palatin Technologies, Takeda; Advisory Board Fee/Consultant Fee: Fabre-Kramer, Palatin Technologies, S1 Biopharma, Sprout a division of Valeant Pharmaceuticals, Takeda; Royalties/Copyright: Ballantine Books/Random House, Changes in Sexual Functioning Questionnaire, Guilford Publications; Shares/ Restricted Stock Units: Euthymics; S1 Biopharma. Drs Parikh and Robinson report no conflicts of interest in this work.

\section{References}

1. Jablensky A. Epidemiology of schizophrenia: the global burden of disease and disability. Eur Arch Psychiatry Clin Neurosci. 2000; 250(6):274-285.

2. Salomon JA, Vos T, Hogan DR, et al. Common values in assessing health outcomes from disease and injury: disability weights measurement study for the Global Burden of Disease Study 2010. Lancet. 2012; 380(9859):2129-2143.

3. Reddy MS. Depression: the disorder and the burden. Indian J Psychol Med. 2010;32(1):1-2.

4. Ferrari AJ, Charlson FJ, Norman RE, et al. Burden of depressive disorders by country, sex, age, and year: findings from the global burden of disease study 2010. PLoS Med. 2013;10(11):e1001547.

5. Whiteford HA, Ferrari AJ, Degenhardt L, Feigin V, Vos T. The global burden of mental, neurological and substance use disorders: an analysis from the Global Burden of Disease Study 2010. PLoS One. 2015; 10(2):e0116820.

6. Maeda K, Lerdrup L, Suqino H, et al. Brexpiprazole II: antipsychoticlike and procognitive effects of a novel serotonin-dopamine activity modulator. J Pharmacol Exp Ther. 2014;351(3):686-687.

7. Rexulti ${ }^{\circledR}$ (brexpiprazole) [full prescribing information]. 2015. Available from: https://www.accessdata.fda.gov/drugsatfda_docs/ label/2015/205422s000lbl.pdf. Accessed January 18, 2016.

8. Stahl SM. Mechanism of action of brexpiprazole: comparison with aripiprazole. CNS Spectr. 2016;21(1):1-6.

9. Ishima T, Futamura T, Ohgi Y, Yoshimi N, Kikuchi T, Hashimoto K. Potentiation of neurite outgrowth by brexpiprazole, a novel serotonindopamine activity modulator: a role for serotonin 5-HT1A and 5-HT2A receptors. Eur Neuropsychopharmacol. 2015;25(4):505-511.
10. Yoshimi N, Fujita Y, Ohgi Y, Futamura T, Kikuchi T, Hashimoto K. Effects of brexpiprazole, a novel serotonin-dopamine activity modulator, on phencyclidine-induced cognitive deficits in mice: a role for serotonin 5-HT1A receptors. Pharmacol Biochem Behav. 2014;124: 245-249.

11. Yoshimi N, Futamura T, Hashimoto K. Improvement of dizocilpineinduced social recognition deficits in mice by brexpiprazole, a novel serotonin-dopamine activity modulator. Eur Neuropsychopharmacol. 2015;25(3):356-364.

12. Howland RH. Brexpiprazole: another multipurpose antipsychotic drug? J Psychosoc Nurs Ment Health Serv. 2015;53(4):23-25.

13. Correll CU, Skuban A, Ouyang J, et al. Efficacy and safety of brexpiprazole for the treatment of acute schizophrenia: a 6-week randomized, double-blind, placebo-controlled trial. Am J Psychiatry. 2015;172(9): $870-880$.

14. Kane JM, Skuban A, Ouyang J, et al. A multicenter, randomized, double-blind, controlled phase 3 trial of fixed-dose brexpiprazole for the treatment of adults with acute schizophrenia. Schizophr Res. 2015; 164(1-3):127-135.

15. Correll CU, Skuban A, Ouyang J, Weiss C, Weiller E, Kane JM. Efficacy and safety of brexpiprazole (OPC-34712) in acute schizophrenia: a pooled analysis of two pivotal studies. Eur Neuropsychopharmacol. 2015;25(supp1 2):S522-S523.

16. Correll CU, Skuban A, Hobart M, et al. Efficacy of brexpiprazole in patients with acute schizophrenia: review of three randomized, double-blind, placebo-controlled studies. Schizophr Res. 2016; 176(1-3):82-92.

17. Lundbeck H. Brexpiprazole in Patients with Acute Schizophrenia. Bethesda, MD: National Library of Medicine (US); 2015.

18. Marder SR, Hakala MJ, Gislum M, et al. An interventional, multicenter, randomized, double-blind, placebo-controlled, active reference, flexible dose study of brexpiprazole in adults with acute schizophrenia. In: 24th European Congress of Psychiatry; Madrid, Spain; 2016.

19. Citrome L, Ota A, Nagamizu K, Perry P, Weiller E, Baker RA. The effect of brexpiprazole (OPC-34712) and aripiprazole in adult patients with acute schizophrenia: results from a randomized, exploratory study. Int Clin Psychopharmacol. 2016;31(4):192-201.

20. Hobart M, Ouyang J, Forbes A, et al. Efficacy and safety of brexpiprazole (OPC-34712) as maintenance treatment in adults with schizophrenia: a randomized, double-blind, placebo-controlled study; Miami, FL: United States: American Society of Clinical Psychopharmacology 2015 Annual Meeting; 2015.

21. Fleischhacker WW, Hobart M, Ouyang J, et al. Brexpiprazole (OPC-34712) efficacy and safety as maintenance therapy in adults with schizophrenia: randomised, double-blind, placebo-controlled study. Eur Neuropsychopharmacol. 2015;25(suppl 2):S527.

22. Citrome L. Brexpiprazole for schizophrenia and as adjunct for major depressive disorder: a systematic review of the efficacy and safety profile for this newly approved antipsychotic - what is the number needed to treat, number needed to harm and likelihood to be helped or harmed? Int J Clin Pract. 2015;69(9):978-997.

23. Thase ME, Youakim JM, Skuban A, et al. Adjunctive brexpiprazole 1 and $3 \mathrm{mg}$ for patients with major depressive disorder following inadequate response to antidepressants: a phase 3, randomized, double-blind study. J Clin Psychiatry. 2015;76(9):1232-1240.

24. Thase ME, Youakim JM, Skuban A, et al. Efficacy and safety of adjunctive brexpiprazole $2 \mathrm{mg}$ in major depressive disorder: a phase 3 , randomized, placebo-controlled study in patients with inadequate response to antidepressants. J Clin Psychiatry. 2015;76(9):1224-1231.

25. McIntyre RS, Weiller E, Zhang P, Weiss C. Brexpiprazole as adjunctive treatment of major depressive disorder with anxious distress: results from a post-hoc analysis of two randomized controlled trials. $J$ Affect Disord. 2016;201:116-123.

26. Davis LL, Ota A, Perry P, Tsuneyoshi K, Weiller E, Baker R. Adjunctive brexpiprazole (OPC-34712) in patients with major depressive disorder and anxiety symptoms: an exploratory study. Biol Psychiatry. 2015; 77(9suppl 1):S66. 
27. Citrome L. The ABCs of dopamine receptor partial agonists-aripiprazole, brexpiprazole, and cariprazine: the 15-min challenge to sort these agents out. Int J Clin Pract. 2015;69(11):1211-1220.

28. Menard F, Fava M, Davidsen CK, Baker RA. Adjunctive brexpiprazole (OPC-34712) in patients with major depressive disorder and irritability: an exploratory study. Biol Psychiatry. 2015;77(9 suppl 1):S65.

29. Krystal A, Mittoux A, Meisels P, Baker R. Adjunctive brexpiprazole (OPC-34712) in patients with major depressive disorder and sleep disturbances: an exploratory study. Biol Psychiatry. 2015;77(9 suppl 1): S64-S65.
30. Skuban A. A Study of Flexible-dose Brexpiprazole as Adjunctive Therapy in the Treatment of Adults with Major Depressive Disorder, the Delphinus Trial. Bethesda, MD: National Library of Medicine (US); 2015.

31. Nelson JC, Skuban A, Zhang P, Weiller E, Weiss C. Long-term safety of adjunctive brexpiprazole (OPC-34712) in MDD: results from two 52-week open-label studies. Poster presentation, 168th Annual Meeting of the American Psychiatric Association Annual Meeting; May 16-20, 2015; Toronto, ON, Canada.

\section{Publish your work in this journal}

Therapeutics and Clinical Risk Management is an international, peerreviewed journal of clinical therapeutics and risk management, focusing on concise rapid reporting of clinical studies in all therapeutic areas, outcomes, safety, and programs for the effective, safe, and sustained use of medicines. This journal is indexed on PubMed Central, CAS,
EMBase, Scopus and the Elsevier Bibliographic databases. The manuscript management system is completely online and includes a very quick and fair peer-review system, which is all easy to use. Visit http://www.dovepress.com/testimonials.php to read real quotes from published authors.

Submit your manuscript here: http://www.dovepress.com/therapeutics-and-clinical-risk-management-journal 